

\title{
Misaligned Union laws? A comparative analysis of certification in the Cybersecurity Act and the General Data Protection Regulation
}

\author{
Irene KAMARA \\ TILT, Tilburg University, The Netherlands \\ i.kamara@uvt.nl \\ Netherlands \\ @uvt.nl
}

TILT Law \& Technology Working Paper No. 002/2020

18 November 2020, Version: 1.0

This paper can be downloaded without charge from the

Social Science Research Network Electronic Paper Collection

https://ssrn.com/abstract=3732846

An overview of the TILT Law \& Technology Working Paper Series can be found at: http://www.tilburguniversity.nl/faculties/law/research/tilt/publications/workingpapers/ 
This is a draft version. Please refer to: Kamara, I. Misaligned union laws? A comparative analysis of certification in the Cybersecurity Act and the General Data Protection Regulation. In D. Hallinan, R. Leenes, \& P. De Hert (Eds.) (2020), Privacy and data protection: Artificial intelligence Hart Publishing.

\begin{abstract}
In 2019, the Cybersecurity Act, the EU law aiming to achieve high level of cybersecurity in the Union and Member States, entered into force. The CSA belongs to a broader set of Union laws providing a framework of legal protection of individual and collective rights from harmful use of information and communication technologies. Those laws introduce private law instruments for the achievement of legislative goals. ${ }^{1}$ Despite the overarching similarities of the regulated fields, the Union legislator adopted seemingly different approaches in introducing private law instruments. The Chapter seeks to comparatively present the certification frameworks as introduced in the Cybersecurity Act and the General Protection Regulation, with the aim to provide an understanding on the legislative choices and the normative, implementation and policy reasons underpinning the introduction of private law instruments in Union laws.
\end{abstract}

Keywords: accreditation, assurance levels, certification, conformity assessment, cybersecurity, data protection, data security, ex ante transparency, risk based approach, trust

\footnotetext{
${ }^{1}$ Codes of Conduct were already regulated in Art. 17 of the Data Protection Directive 95/46/EC, but largely unused in practice. See Irene Kamara, "Commentary Article 40" in The European General Data Protection Regulation (GDPR) A Commentary, ed. Chrisopher Kuner, Lee Bygrave, and Christopher Docksey, (Oxford University Press 2020).
} 


\section{Introduction}

In 2019, the Cybersecurity Act ('CSA'), the EU law aiming to achieve high level of cybersecurity in the Union and Member States, entered into force. ${ }^{2}$ The Regulation has two main pillars: the update of the mandate of ENISA as the European Union Agency for Cybersecurity, and the introduction of a framework for cybersecurity certification. The two pillars of the CSA aim at addressing the increased cybersecurity challenges, which businesses, organisations, and citizens face in the Union. The urgency for the adoption of legislation and policies in the field of cybersecurity has been spurred by technological developments that enable monitoring and surveillance of individuals, in combination with proven misuse and abuse of such technologies, as demonstrated in several cases brought before national courts, the Court of Human Rights, and the Court of Justice. ${ }^{3}$

In its 2013 Cybersecurity Strategy, the European Commission emphasised the need for effective protection of citizens' rights, especially those rights enshrined in the Charter of Fundamental Rights of the European Union. ${ }^{4}$ The CSA belongs to a series of policy and legislative endeavours of the Union to enhance its cybersecurity capacity and resilience, and arguably provide a framework of legal protection of individual and collective rights from harmful use of information and communication technologies (ICT). The CSA was adopted a few years after the Network and Information Security Directive (NIS), ${ }^{5}$ which was a first 'essential step' for the introduction of security requirements as legal obligations. ${ }^{6}$ Moreover, in 2018, the General Data Protection Regulation (GDPR) started applying, together with the Law Enforcement Directive (LED), and in 2017 the European Commission set forward a proposal for an ePrivacy Regulation, regulating privacy and confidentiality in electronic communications. ${ }^{7}$

From a legal design perspective, the new Union laws for the protection of personal data and information, present a relative novelty of introducing inter alia private law instruments for the achievement of their legislative goals. Technical specifications, standards, and certifications, were previously in the shadow of 'information protection laws' in the Union. Certifications in particular were largely developed in areas that were not harmonised under Union law. ${ }^{8}$ The choice of the legislator to utilise those instruments emanates from

\footnotetext{
${ }^{2}$ Regulation (EU) 2019/881 of the European Parliament and of the Council of 17 April 2019 on ENISA (the European Union Agency for Cybersecurity) and on information and communications technology cybersecurity certification and repealing Regulation (EU) No 526/2013 (Cybersecurity Act) OJ L 151, 7.6.2019.

${ }^{3}$ Bart Van der Sloot, and Eleni Kosta, "Big brother watch and others v UK: Lessons from the latest Strasbourg ruling on bulk surveillance", European Data Protection Law Review 5, No. 2, p. 252 -261; Judgment of the Court (Grand Chamber) of 6 October 2015. Maximillian Schrems v Data Protection Commissioner. Request for a preliminary ruling Case C-362/14. C:2015:650; Case C-623/17: Reference for a preliminary ruling from the Investigatory Powers Tribunal — London (United Kingdom) made on 31 October 2017 - Privacy International v Secretary of State for Foreign and Commonwealth Affairs and Others.

${ }^{4}$ Joint Communication to the European Parliament, the Council, the European Economic and Social Committee and the Committee of the Regions, "Cybersecurity Strategy of the European Union: An Open, Safe and Secure Cyberspace" 7.2.2013 JOIN (2013) final, p. 3.

${ }_{5}$ Network and Information Security Directive (2016) Directive (EU) 2016/1148 of the European Parliament and of the Council of 6 July 2016 concerning measures for a high common level of security of network and information systems across the Union OJ L 194, 19.7.2016.

${ }^{6}$ European Commission, explanatory memorandum CSA.

${ }^{7}$ Regulation (EU) 2016/679 of the European Parliament and of the Council of 27 April 2016 on the protection of natural persons with regard to the processing of personal data and on the free movement of such data, and repealing Directive 95/46/EC (General Data Protection Regulation, OJ L 119, 4.5.2016; Directive (EU) 2016/680 of the European Parliament and of the Council of 27 April 2016 on the protection of natural persons with regard to the processing of personal data by competent authorities for the purposes of the prevention, investigation, detection or prosecution of criminal offences or the execution of criminal penalties, and on the free movement of such data, and repealing Council Framework Decision 2008/977/JHA OJ L 119, 4.5.2016; Proposal for a of the European Parliament and of the Council concerning the respect for private life and the protection of personal data in electronic communications and repealing Directive 2002/58/EC (Regulation on Privacy and Electronic Communications) COM/2017/010 final.

${ }^{8}$ Andreas Mitrakas, "The emerging EU framework on cybersecurity certification." Datenschutz und Datensicherheit-DuD 42, no. 7 (2018): 411-414.
} 
a need to regulate tools that already existed in the market, ${ }^{9}$ but also leverage the accumulated experience from using such instruments and direct it to specific legislative goals such as demonstrating compliance with legal obligations or enhancing the harmonised effects of the Union law. Those instruments are in essence voluntary, with the potential to influence whether and how regulatees comply with the corresponding law.

The aim of the Chapter is to provide an understanding of the legislative choices and the normative, implementation and policy reasons underpinning the introduction of private law instruments in Union laws. The article therefore seeks to analyse certification as introduced in the Cybersecurity Act and the General Protection Regulation. The two laws are selected because of their explicit legal provisions on such instruments, the time proximity with which they were adopted, and their legal classification as Regulations. The underlying assumption of the article is that because of the link between the legislation on cybersecurity and protection of personal data, which can be broadly framed as serving (among other goals) a goal of protecting information, ${ }^{10}$ the two laws would follow a similar approach with regard to private law instruments. ${ }^{11}$ Even more, if one considers that the entities legally obliged to comply with the cybersecurity and data protection legislation are very often the same. Therefore, an aligned approach towards certification in these laws would allow for common requirements and mutual recognition of certifications. On the other hand, issues may arise from divergent approaches; market 'pollution' 12 and legal uncertainty among the regulatees, potential conflicting requirements following CSA and GDPR certifications on similar subject matters, increased costs, and ultimately undermining of the goal of certification as a transparency, trust, and harmonisation instrument.

The Chapter follows an analytical legal comparative method, comparing the rules on certification in the Cybersecurity Act and the GDPR. ${ }^{13}$ The development and governance of certifications serves as tertium comparationis. The aims of the Chapter require to not target only the differences or only similarities of the compared rules, but identify both aspects for a comprehensive in-depth understanding of both certification frameworks. Moreover, the Chapter does not claim to provide a systematic analysis of the certification frameworks, which means that some procedural or other aspects are not included in the analysis, nor does it assess the strengths and weaknesses of each framework in achieving its intended legislative goals. Last, whereas there is value in general in exploring other private law instruments such as codes of conduct, the Chapter's scope is focused on certification and does not extend to such other instruments.

The Chapter is structured as follows. First, the certification frameworks in the Cybersecurity Act and following that the GDPR are presented in sections two and three. Sections four and five provide the comparative analysis of the certification frameworks in the Cybersecurity Act and the General Data Protection Regulation and elements of divergence and convergence respectively. Section six provides the discussion on the findings and responds to the research questions of the article, and section seven summarises and concludes the article.

\section{The European Cybersecurity certification framework in the Cybersecurity Act}

The Cybersecurity Act establishes a framework for the development and operational life cycle of cybersecurity certification schemes. Besides the identified need for bottom-up

\footnotetext{
${ }^{9}$ Gerrit Hornung, "A General Data Protection Regulation for Europe: Light and Shade in the Commission's Draft of 25 January 2012." SCRIPTed 9 (2012): 64.

10 See Section 5.3 p.13f.

11 This shared goal and intersection between the CSA and the GDPR is evident from policy documents such as the Commission Evaluation Report for the two years of GDPR application COM (2020) 264 final p.10.

${ }_{12}$ See Irene Kamara, Ronald Leenes, et al. "Data protection certification mechanisms: Study on Articles 42 and 43 of the Regulation (EU) 2016/679. Annexes" Publications Office of the EU (2019), Annex 6.

${ }^{13}$ Mark, Van Hoecke, "Methodology of comparative legal research." Law and method (2015): 1-35.
} 
governance and dynamic stakeholder regulation, ${ }^{14}$ the Cybersecurity certification framework addresses a need for a common approach in the Union and horizontal requirements for European cybersecurity. ${ }^{15}$ Common measures ensure that the capabilities of every actor in the chain of for example an ICT service are transparent, auditable, and comparable. This aspect is of relevance in particular to cybersecurity, due to the high degree of interdependence of ICT products, processes, and services on third party technologies and components. ${ }^{16}$ At the same time, common requirements across the Union would eliminate companies' costs for recertification in each Member State.

The CSA provides an elaborate framework on certification. The drafting of certification schemes, ${ }^{17}$ the governance, the supervision of the granted certifications, and other aspects of certification are outlined in the legal provisions in a detailed manner, one that does not leave much room for manoeuvre to certification bodies and Member States. To some extent, this was a necessary step mandated by the nature of cybersecurity and the need for coherent measures across the chain of components and lifecycle of the product, process, or service, since one vulnerability or inconsistency might be enough to undermine the overall level of security. The prescriptive nature of the framework received criticism during the preparatory works in the law-making process. ${ }^{18}$ The Commission proposal followed a much more defined/regulated model than the one adopted, in line with the New Legislative Framework and harmonised standards.

As per the framework itself, two phases can be distinguished: the development of the schemes and the implementation (governance) phase, after a certification scheme is adopted. Main actors in the development phase are the Commission and ENISA, with the support of various stakeholders, while in the implementation phase national cybersecurity certification authorities and certification bodies take on the significant roles of granting and supervising certifications.

\subsection{Development of European cybersecurity certification schemes}

The procedure for the development and adoption of a cybersecurity scheme is initiated by the European Commission, which requests ENISA to prepare a European cybersecurity certification candidate scheme. The Commission request is in principle based on the Union rolling work programme, ${ }^{19}$ which is an annual Commission publication outlining strategic priorities for cybersecurity certification schemes. ${ }^{20}$ The Commission or the ECCG may also request ENISA to prepare a candidate scheme that

\footnotetext{
${ }^{14}$ Rolf H. Weber and Evelyne Studer, "Cybersecurity in the Internet of Things: Legal aspects." Computer Law \& Security Review 32, no. 5 (2016): 715-728.

15 Recital 69 CSA.

${ }^{16}$ Recital 10 CSA.

17 In the Cybersecurity Act, a European cybersecurity certification scheme is defined as a "comprehensive set of rules, technical requirements, standards and procedures that are established at Union level and that apply to the certification or conformity assessment of specific ICT products, ICT services or ICT processes" Art. 2(9) CSA. More broadly, international standards define a conformity assessment scheme (one type of which are certification schemes) as "rules, procedures and management for carrying out conformity assessment" "elated to specified objects of conformity assessment, to which the same specified requirements, specific rules and procedures apply". See ISO/IEC 17000 Conformity assessment - Vocabulary and general principles.

${ }^{18}$ European Commission, Proposal for a Regulation of the European Parliament and of the Council on ENISA, the "EU Cybersecurity Agency", and Repealing Regulation (EU) 526/2013, and on Information and Communication Technology Cybersecurity Certification ("Cybersecurity Act"), COM (2017) 477 final; Criticism on the Commission proposal (2017) Kai Peters "Cybersecurity Act: EU must do better!" VDMA blog, https://www.vdma.org/en/v2viewer/-/v2article/render/24584915 (accessed 31st March 2020). Read on the New Legislative Framework: Linda Senden, "The Constitutional Fit of European Standardization Put to the Test." Legal Issues of Economic Integration 44, no. 4 (2017): 337-352; Carlo Colombo, and Mariolina Eliantonio, "Harmonized technical standards as part of EU law: Juridification with a number of unresolved legitimacy concerns? Case C-613/14 James Elliot Construction Limited v. Irish Asphalt Limited, EU: C: 2016: 821." Maastricht Journal of European and Comparative Law 24, no. 2 (2017): 323-340.

${ }^{19}$ Art. 48(1) CSA.

${ }^{20}$ Art. 47(1) CSA.
} 
is not based on the Union rolling work programme, but in this case the request should be 'duly justified'. ${ }^{21}$ It should be noted that despite what the use of the wording 'request' implies, ENISA is obliged ("shall") to follow the Commission's 'request' and prepare a candidate scheme. ${ }^{22}$ This is not the case however for the ECCG request, the acceptance of which lies at the discretion of ENISA. ${ }^{23}$ ENISA prepares the candidate schemes, with the assistance of an ad hoc working group and the ECCG, which provides non-binding expert advice. Once the draft candidate scheme is finalised, ENISA submits it to the Commission, which has the power to adopt it with an implementing act. ${ }^{24}$

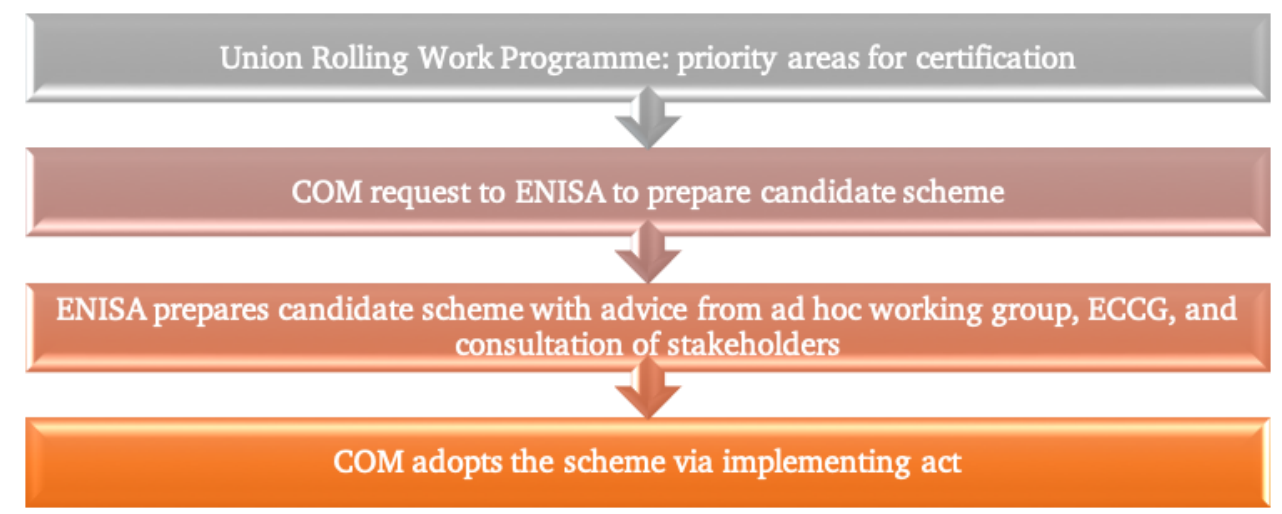

Figure 1: Development and adoption procedure of a certification scheme under the Cybersecurity Act

When preparing the candidate scheme, ENISA is not entirely free to decide on its content. On top of the goals and requirements outlined in the request, the basic yet essential elements of European cybersecurity certification schemes are provided in a non-exhaustive list in the Regulation. ${ }^{25}$ The legislator aimed at ensuring in this way that all the schemes share a common structure and address the same significant issues. The manner in which they address those issues will inevitably differ depending on the scope, sector, context of the scheme.

Certification schemes provide requirements, on the basis of which the level of cybersecurity of an ICT product, ICT process, or ICT service may be assessed. The schemes to be established under the European cybersecurity certification framework need to be designed to achieve a minimum number of security goals, provided in Art. 51 CSA, such as for example security by default ${ }^{26}$ and protection of data against accidental or unauthorised storage, processing, access or disclosure. ${ }^{27}$ To better determine the level of assurance of the European cybersecurity schemes, the Regulation provides for different assurance levels -basic, substantial, high - that correspond to the level of risk associated with the intended use of the ICT product, ICT process, or ICT service. Quite remarkable is the standstill obligation, similar to what exists in European standardisation and harmonised standards: national schemes cease to produce effects, once a European cybersecurity scheme is adopted with the same scope. ${ }^{28}$

\footnotetext{
${ }^{21}$ The experience so far shows that the legal standard for this justification is not prohibitively high, since two certification schemes are currently being prepared before the adoption of the first Union rolling Work program : See ENISA https://www.enisa.europa.eu/news/enisa-news/enisa-cybersecurity-certificationpreparation-underway (accessed 31st March 2020).

${ }^{22}$ Art. 49(1) CSA.

${ }^{23}$ Art. 49(2) CSA "[..]ENISA may prepare a candidate scheme [...]" (emphasis added)

${ }^{24}$ Read further on implementing acts: Steve Peers and Marios Costa, "Accountability for delegated and implementing acts after the Treaty of Lisbon." European Law Journal 18, no. 3 (2012): 427-460.

25 Art. 54 CSA. Those include elements such as the subject matter and scope of the scheme, the type or categories of ICT products, systems, services covered, the purpose of the scheme, references to technical standards or specifications, the possibility for conformity self-assessment, additional accreditation requirements for conformity assessment bodies, specific evaluation criteria, the use of marks and labels, rules for monitoring compliance, conditions for the certificates, and others.

${ }^{26}$ Art. 51 (1)(i) CSA.

${ }^{27}$ Art. 51 (1)(a) CSA.

28 Art. 57(1) CSA.
} 


\subsection{Governance of European cybersecurity certification schemes}

Once a certification scheme is adopted by the European Commission and published in the Official Journal, the competent entities may start working to make it operational, so that manufacturers or providers can apply and have their products, processes, or services certified. Before explaining how the implementation phase works, a remark is in order. While the framework primarily refers to third party conformity assessment (certification), it does allow manufacturers or providers to assess their own ICT product, process, or service following the requirements of the certification scheme and issue an EU statement of conformity. ${ }^{29}$ Conformity self-assessment is allowed only for low risk ICT products, processes, and services (basic assurance level). The EU statement of fulfillment is not a certificate, but a self-declaration of conformity, binding for the issuing manufacturer or provider, who 'assumes responsibility for the compliance' and can be held accountable for it. ${ }^{30}$ In terms of effects however, a certificate is always more reliable than an EU statement of fulfillment, since it involves an assessment from an independent third party.

Certification is offered in principle by certification bodies, which are private organisations. Certification bodies need to be accredited by the national Accreditation Body in the MS of their establishment. ${ }^{31}$ Accreditation is a necessary condition for the competence of a certification body to provide services on European cybersecurity certification scheme. In exceptional cases, the Regulation provides that the national competent cybersecurity certification authority may also issue certifications. This power of the national authorities is introduced as a derogation to the general rule that certification bodies issue certificates, but the conditions are not further specified in the Regulation. ${ }^{32}$ Interestingly, the legislator does not presume the competence of national authorities to issue certificates; like certification bodies, the authorities must be accredited as conformity assessment bodies. ${ }^{33}$

Natural and legal persons that are manufacturers or providers of ICT products, ICT services, or ICT processes qualify as applicants for European cybersecurity certification. ${ }^{34}$ The CSA gives the opportunity to both types of entities to apply, recognising an interest for being awarded cybersecurity certification. Manufacturers and providers may apply for cybersecurity certification to the conformity assessment body of their choice anywhere in the Union. ${ }^{35}$ Thus, a legal person is not bound by some territoriality criterion such as the jurisdiction of the main establishment, as long as it is established in the Union. The risk of forum-shopping, i.e. applicants applying to the conformity assessment body with the most favourable or lenient approach, is expected to be mitigated by the fact that those certification bodies follow the same rules, a common baseline, which is the European cybersecurity certification scheme. This offers some guarantees that differences in the approaches of the certification bodies, will not be detrimental to the quality of the evaluation outcomes, thus achieving a common or comparable quality level. In addition, the obligation for a peer review mechanism, which subjects all the national cybersecurity authorities to evaluations by their 'peers' namely the competent authorities of the other MS, is an additional safeguard against forumshopping.

Certifications are issued to the applicants after a successful evaluation by the conformity assessment body, based on the requirements and the evaluation methods and standards described in the scheme. ${ }^{36}$ The validity of the certifications is different from scheme to

\footnotetext{
${ }^{29}$ Art. 53 CSA.

${ }^{30}$ Recital 81 CSA.

${ }^{31}$ Art. 7(1) Regulation 765/2008 of the European Parliament and of the Council of 9 July 2008 setting out the requirements for accreditation and market surveillance relating to the marketing of products and repealing Regulation (EEC) No 339/93 OJ L 218/

${ }^{32}$ Art. 56(5)(a) CSA.

${ }^{33}$ Art. 60(2) CSA.

${ }^{34}$ Rec. 97 CSA.

35 lbid.

${ }^{36}$ Art. 54(1) (b), (c), and (g).
} 
scheme. Some certifications need to have short validity period, as the schemes require regular revisions to keep up with technological developments that might render the requirements and methods prescribed in those schemes obsolete, some others, for example relating to organisational issues and management, might have a longer expiration date. ${ }^{37}$ Responsible for the supervision and enforcement are the certification bodies and the national cybersecurity certification authorities, ${ }^{38}$ which also handle complaints against issued certificates. ${ }^{39}$

\section{The data protection certification mechanisms in the General Data Protection Regulation}

The GDPR introduces personal data protection certification in Arts. 42 and 43 . Article 42 provides rules and characteristics of certification, the "data protection certification mechanisms", while Article 43 is mostly dedicated to the bodies providing certification services. The rationale for introducing certification in the reformed EU data protection law is described in Recital 100:

"In order to enhance transparency and compliance with this Regulation, the establishment of certification mechanisms and data protection seals and marks should be encouraged, allowing data subjects to quickly assess the level of data protection of relevant products and services." 40

Certification per Art. 42(1) has a twofold function. To assist the regulatees, e.g. data controllers and processors, demonstrate how they comply with the law, and to offer insights into the activities of the controllers and processors to the individuals whose data are processed (data subjects). The help towards regulatees to comply with the law and demonstrate this via certification to supervisory authorities is envisioned to materialise in several manners, for example with certifications that 'translate' legal obligations to tangible controls, measures, and policies for organisations, or adapt requirements to needs and specificities of different sectors.

The legislative history of the provision (former Art. 39 in the Commission proposal) reveals a multitude of rationales and approaches, ranging from a stringent certification system with strong oversight in the European Parliament First Reading 2014 version to some looser system where public and private actors intertwine in the Council General Approach (Articles 39 and 39a). The final text of the GDPR is a compromise among different visions of the EU co-legislators. ${ }^{41}$ It retains the oversight by the independent data protection authorities (DPAs), which was an element of the Parliament version, but it also allows private entities - that is certification bodies - in parallel to the DPAs, to grant certifications. The Commission and the Member States are obliged to encourage the development of certifications, which are voluntary per Art. 42(1).

\footnotetext{
${ }^{37}$ Common Criteria, which are a well-accepted certification in the information security market, provide a distinction between technical validity of the issued certificates and administrative validity. Administrative validity is "related to administrative tasks such as advertising of certificates on a Certified Products List and archiving of evaluation evidence"; technical validity relates to the resistance of the certified product to attacks. While the administrative validity period of the certificate is 5 years, it is interesting that in relation to the technical validity is stated that: "[...], certificates can only be considered technically valid at their time of issuance. Indeed, because the evolution of the state-of-the-art regarding attack methods cannot be predicted, there can be no time period associated to the technical validity of a certificate." See SOG-IS Recognition Agreement Management Committee, "SOG-IS certificate validity v1.0.doc", version 1, (no date) https://www.sogis.eu/documents/mra/SOG-IS-certificate-validity-v1.0.pdf

38 Art. 58(7) (a), (b), (e) CSA.

${ }^{39}$ Art. 58(7)(h) CSA and Art. 63(1) CSA.

40 Recital 100 GDPR.

${ }^{41}$ Irene Kamara and Paul De Hert, "Data protection certification in the EU: Possibilities, actors and building blocks in a reformed landscape." In Privacy and data protection seals, eds. Rowena Rodrigues and Vagelis Papakonstantinou, pp. 7-34. TMC Asser Press, The Hague, 2018.
} 


\subsection{Development of data protection certifications}

The GDPR envisages both national and European certifications. The former concern a national jurisdiction of a Member State, whereas the European certifications (European Data Protection Seals) are pan-European and supervised by the European Data Protection Board. The development of data protection certification is not prescribed in the GDPR. The drafting of a certification scheme, including the criteria to be used for assessing the conformity of the data processing operation, may therefore be performed by any interested entity. Certification bodies, standardisation bodies, industry or industry consortia, consumer associations may draft certification criteria. Supervisory authorities may take on such a role as well. However, this possibility has raised concerns for risks of function creep, competition among DPA-run certifications, and overburden the resources of the authorities. ${ }^{42}$

Since, the GDPR data protection certifications are multi-layered constructs, ${ }^{43}$ there are more stages in the development thereof. The competent data protection authority for national certifications or the European Data Protection Board for EU level certifications are tasked to approve the criteria of the candidate schemes. It is questionable whether the supervisory authorities should be restricted by a literal interpretation of their task and limit the assessment and approval to the 'criteria' only, or instead conduct a comprehensive examination of the certification mechanism as a whole. The latter would seem the most reasonable approach towards securing the quality and reliability of data protection certifications. The process and act of approval can be viewed as a balancing factor to the complete lack of limitations in the GDPR on which actor drafts the criteria. Since any interested party can draft criteria for certification, the burden of the DPA to assess and approve the criteria is of paramount importance for the quality of the resulting certification. After a certification mechanism is developed and received the approval of the supervisory authority, it is published in a publicly available register, maintained by the EDPB. ${ }^{44}$ Additionally, supervisory authorities are tasked to publish certification criteria per Art. 42(5) and the accreditation requirements for certification bodies per Art. 43 (3) and transmit both criteria and requirements to the Board. ${ }^{45}$

\subsection{Governance of data protection certifications}

Certifications per Art. 42 GDPR are voluntary, do not reduce the responsibility of a data controller or processor to comply with the legal obligations, neither do they offer a presumption of conformity with the law. The supervisory authorities maintain their regular supervisory powers for compliance with the GDPR, independently of a certification granted to a controller or a processor. ${ }^{46}$ Two types of entities/persons qualify to apply for certification: data controllers and processors. The legislator intentionally refers to persons that are involved in the processing of personal data, and thus excludes manufacturers, due to the material scope of the Regulation. ${ }^{47}$

\footnotetext{
${ }^{42}$ Rowena Rodrigues, David Barnard-Wills, Paul De Hert, and Vagelis Papakonstantinou. "The future of privacy certification in Europe: an exploration of options under article 42 of the GDPR." International Review of Law, Computers \& Technology 30, no. 3 (2016): 248-270.

43 Ronald Leenes, "Commentary Article 42" in The European General Data Protection Regulation (GDPR) A Commentary, ed. Chrisopher Kuner, Lee Bygrave, and Christopher Docksey, (Oxford University Press 2020) p.739.

${ }^{44}$ Art. 42(8) GDPR.

${ }^{45}$ Art. 43(6) GDPR.

${ }^{46}$ Art. 42(4) GDPR.

${ }^{47}$ Art. 2(1) GDPR provides: "This Regulation applies to the processing of personal data wholly or partly by automated means and to the processing other than by automated means of personal data which form part of a filing system or are intended to form part of a filing system."
} 


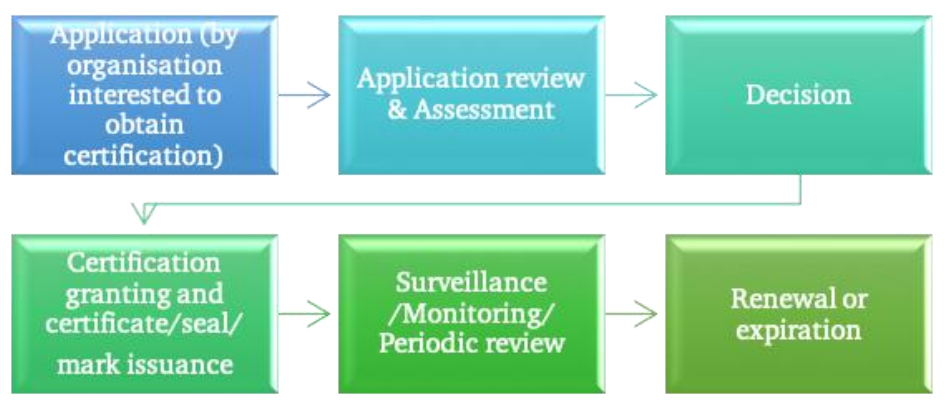

Figure 2: Certification procedure per Arts. 42 and 43 GDPR.

The procedure for an entity to apply and be awarded certification follows stages that are familiar to practitioners working in conformity assessment. ${ }^{48}$ Depending on the Member State, certification bodies and/or data protection supervisory authorities conduct the evaluation of the application and issue certifications. When the certification process is conducted by a certification body, this body needs to be an accredited one. The GDPR provides three models for the accreditation of certification bodies. ${ }^{49}$ Accreditation may be conducted by the competent supervisory authority, the National Accreditation Body with the support of the supervisory authority, or both. In practice, most Member States followed one of the models that involves the National Accreditation Body (NAB), ${ }^{50}$ presumably due to the accumulated experience of the NAB to conduct assessments on the independence, integrity, competence, and overall suitability of a conformity assessment body to conduct assessments in a given field following standards and certification schemes.

The assessment is conducted against the set of certification criteria approved by the competent supervisory authority or the EDPB. The applicant is obliged to provide the certification body with all relevant information and provide access to its activities, thus to facilitate the assessment. ${ }^{51} \mathrm{~A}$ successful assessment leads to awarding certification, and issuing a certificate (seal and mark) to the applicant. The GDPR places the responsibility for ensuring a proper assessment on certification bodies, when those are issuing the certification. ${ }^{52}$ There is no indication in the GDPR however on how the assessment should take place, what constitutes a sufficient assessment result, whether some nonconformities should be accepted. Those issues could therefore differ from certification to certification. The European Data Protection Board has stressed the importance of using appropriate evaluation methods (documentation, onsite visits, etc.) and adjusting the depth and granularity of the certification procedures to the target of evaluation. ${ }^{53}$ Supervisory authorities and certification bodies after informing the authorities, have the power to renew ${ }^{54}$ and withdraw certifications. ${ }^{55}$ Withdrawal of a certification occurs upon the expiration after a three year period from the issuing of the certificate or prematurely when the criteria for certification are not met or due to changes to the conditions under which the assessment took place, the criteria are no longer met. ${ }^{56}$

\footnotetext{
48 ISO/IEC 17065:2012 Conformity assessment - Requirements for bodies certifying products, processes and services. See Figure 2.

${ }^{49}$ Read further on the accreditation models in the GDPR in Irene Kamara, Ronald Leenes, et al. "Data protection certification mechanisms: Study on Articles 42 and 43 of the Regulation (EU) 2016/679. Final Report" Publications Office of the EU (2019), p. $102 f$.

${ }^{50}$ See survey among Data Protection Authorities and National Accreditation Bodies Irene Kamara et al. Annexes (2019).

${ }^{51}$ Art. 42(6) GDPR.

52 Art. 43(4) GDPR.

53 European Data Protection Board, "Guidelines 1/2018 on certification and identifying certification criteria in accordance with Articles 42 and 43 of the Regulation", v.3 2019.

54 Art. 43(1) GDPR

${ }^{55}$ Art. 43(5) and Art. 58(2)(h) GDPR.

${ }^{56}$ Art. 42(7) GDPR.
} 


\section{Divergence}

The description of the CSA and the GDPR frameworks already reveals differences on a number of aspects. This section comparatively presents such aspects with a view to understanding the specific elements of divergence in the models, which are more in depth analysed in Section 6.

\subsection{Centralised v. decentralised approach}

The certification frameworks in the CSA and the GDPR follow a different approach in relation to the development and the territorial outreach of the certificates. The CSA cybersecurity certification framework adopts a centralised approach, with the Commission and ENISA playing pivotal roles in the development and publication of candidate schemes. The GDPR certification framework is a largely decentralised system. Any interested entity may draft schemes and submit them for approval to competent authorities at national level. While the intention of the legislator to stir developments at Union level is there - the possibility for a European Data Protection Seal with the involvement of the European Data Protection Board - the GDPR certification framework is primarily designed around national certifications and a multitude of scheme drafters. ${ }^{57}$ The CSA framework involves several parties as well, but with primarily advisory role in the development process. Examples are the European Cybersecurity Certification Group (ECCG), and the ad hoc working groups, advising and assisting ENISA to develop the candidate schemes. Further, priority is assigned to European cybersecurity certifications over national ones, with an explicit legal provision. The 'standstill' obligation of Art. 57 CSA, according to which national certifications cease to produce effects and MS are not allowed to introduce new national cybersecurity certification schemes for ICT products, services, and processes that are already covered by a European cybersecurity certification scheme, demonstrates the centralised approach of the CSA framework. In the GDPR, only the consistency of national certifications with European Data Protection Seals can be assumed. ${ }^{58}$ There is no formal prioritisation of the common certification, the European Data Protection Seal, over the national ones, and in principle different certification schemes with the same scope may co-exist at national and Union level.

\subsection{Risk based approach and scalability in certification}

The CSA cybersecurity certification framework is admittedly more granular than the GDPR certification mechanisms. First, it provides for both conformity self-assessments and third party certifications. Second, it provides for assurance levels. ${ }^{59}$ As regards selfassessments, the option for manufacturers and service providers to self-assess their conformity to the requirements of the cybersecurity scheme and issue a statement of conformity did not exist in the Commission Proposal, ${ }^{60}$ but was introduced in the Parliament First Reading. ${ }^{61}$ Two elements stand out; one is that conformity self-

\footnotetext{
57 The legislative intention for a centralised system, was also apparent in the Commission Proposal (2012), according to which (Art. 39(2)): "The Commission shall be empowered to adopt delegated acts in accordance with Article 86 for the purpose of further specifying the criteria and requirements for the data protection certification mechanisms referred to in paragraph 1, including conditions for granting and withdrawal, and requirements for recognition within the Union and in third countries." However, the Parliament First Reading was in favour of more elaborate provisions, and proposed the limitation of the Commission powers to adopt legislative acts. Read further: Irene Kamara and Paul De Hert (2019). 58 Art. 63 GDPR.

${ }^{59}$ Assurance levels are defined in Art. 2(21) CSA as "basis for confidence that an ICT product, ICT service or ICT process meets the security requirements of a specific European cybersecurity certification scheme, indicates the level at which an ICT product, ICT service or ICT process has been evaluated but as such does not measure the security of the ICT product, ICT service or ICT process concerned"

${ }^{60}$ Proposal for a Regulation of the European parliament and of the Council on ENISA, the "EU Cybersecurity Agency", and repealing Regulation (EU) 526/2013, and on Information and Communication Technology cybersecurity certification ("Cybersecurity Act") COM/2017/0477 final. 61 European Parliament legislative resolution of 12 March 2019 on the proposal for a regulation of the European Parliament and of the Council on ENISA, the "EU Cybersecurity Agency", and repealing
} 
assessments are allowed only for low risk ICT products, services and processes, and they need to be explicitly allowed by the scheme itself. ${ }^{62}$ The other element is that compliance with the self-assessments is monitored from the national cybersecurity supervisory authorities. ${ }^{63}$ The GDPR allows only third party certifications in the scope of Art. 42. An intention for scalability of some sort is revealed in Art. 42(1), which provides that "the specific needs of micro, small and medium-sized enterprises shall be taken into account." However, this intention is not further supported in the design of the framework, neither elaborated in the Regulation. The EDPB has attempted to flesh out this obligation by explaining that certification criteria should be flexible and scalable for application to different sizes and types of organisations, adopting a risk-based approach. ${ }^{64}$ The EDPB provided the example of a local retailer that would probably carry out "less complex processing operations" than a multinational retailer. ${ }^{65}$ Nevertheless, SMEs owning a health tracking or a geolocation app such as the ones being adopted by several governments recently due to the COVID19 pandemic, ${ }^{66}$ are likely to conduct as risky data processing as large enterprises. Thus, the size of the organisation does not rule out automatically the high risk of processing factor.

When it comes to assurance levels in the CSA certification framework, those are a good example of risk based approach, since the assurance levels are proportionate to "the level of risk associated with the intended use" of ICT products, services or processes. ${ }^{67}$ Interesting here is the weight on the "intended use". The product, service, or process is evaluated considering the environment and context in which it is intended to be used, to ensure a more "reliable and fine-grained description of the security level." 68 Since manufacturers may apply for certification of their products, the assessment is possible only on an intended use instead of actual use, since the latter is known after the ICT product is purchased. At the same time, this focus on the intention reveals the limitations of certification, which does not offer an image of the risks stemming from the actual use. Developing a certification taking account the use and the operational environment, while possible, will not be part of the same evaluation process and certification. ${ }^{69}$

Overall, the establishment of assurance levels in the CSA demonstrates the granular approach in full, as first, the assurance level is related to the level of the risk, ${ }^{70}$ and provides the "rigour and depth of the evaluation"71, second, depending on assurance level, certifications may be issued by public or private authorities, ${ }^{72}$ and third, a certification scheme may provide for different assurance levels. ${ }^{73}$

Regulation (EU) 526/2013, and on Information and Communication Technology cybersecurity certification ("Cybersecurity Act") (COM(2017)0477 - C8-0310/2017 - 2017/0225(COD)).

62 Art. 53(1) CSA.

${ }^{63}$ Art. 58(7)(b) CSA.

${ }^{64}$ Recital 77 GDPR. EDPB Guidelines (2019) p. 20.

65 lbid.

${ }^{66}$ See examples of Dutch (NLtimes 8 April 2020 https://nltimes.nl/2020/04/08/govt-plan-use-apps-trackcovid-19-raises-privacy-concerns), UK (Forbes 12 April 2020

https://www.forbes.com/sites/davidphelan/2020/04/12/covid-19-uk-government-unveils-contact-tracingphone-app-as-next-step-in-fighting-disease/), and Australian governments (The Guardian, 14 April 2020 : https://www.theguardian.com/australia-news/2020/apr/14/australian-government-plans-to-bring-inmobile-phone-app-to-track-people-with-coronavirus)

${ }_{67}$ Recital 78 CSA. Those were not introduced without scepticism from the market and standardisation bodies: ETSI, ETSI Position Paper on draft Regulation 2017/0225 "Cybersecurity Act" (2018) https://www.etsi.org/images/files/ETSI position paper-CyberAct 20180206.pdf 68 Sara N. Matheu Jose L. Hernandez-Ramos, and Antonio F. Skarmeta. "Toward a cybersecurity certification framework for the Internet of Things." IEEE Security \& Privacy 17, no. 3 (2019): 70.

69 ENISA, "Advancing Software Security in the EU - The role of the EU cybersecurity certification framework" (2019) p. 11.

70 Recital 78 CSA.

${ }^{71}$ Recital 86 CSA.

72 Recital 77 CSA.

73 Recital 87 CSA. 


\subsection{Legal effects and penalties}

A third significant point of divergence between the two frameworks concerns the legal effects of the granted certifications. While in both frameworks, certifications demonstrate compliance with the requirements included in the scheme, ${ }^{74}$ and not directly the legislation as such, the CSA leaves the latter open as a possibility. In Art. 54 CSA it is provided that a European Cybersecurity certificate or an EU statement of conformity issued under such a scheme "may be used to demonstrate the presumption of conformity with requirements of that legal act," where a specific Union legal act provides it. ${ }^{75}$ This practically entails a reversal of burden of proof, whereby the certification holder is presumed to comply with the law and the counter party needs to prove the opposite. In addition, the CSA cybersecurity schemes may become mandatory in some areas for specific ICT products, services, or processes. ${ }^{76}$ On the other hand, as mentioned earlier, ${ }^{77}$ the GDPR explicitly provides that certifications are voluntary and do not reduce the responsibility of the regulatees to comply with the legislation. ${ }^{78}$ In case of a violation of an obligation, a controller or processor which are certification holders, still have to demonstrate the measures they took to comply with the law. The presence of certification does not reverse the burden of proof and does not offer any benefit of presumed compliance with the law. The ultimate purpose of data protection certifications is in broad terms to offer transparency for data subjects ${ }^{79}$ and indirectly in the long term enhance compliance with the law, since the certification criteria are based on the GDPR. Although not provided in the GDPR, the Article 29 Data Protection Working Party had supported the view that "non-compliance with self-regulatory measures could also reveal the controller's/processor's negligence or intentional behaviour of non-compliance". ${ }^{80}$

Moreover, there is a substantial difference between the two certification frameworks when it comes to penalties: the GDPR introduces a (high) upper limit for administrative fines for violation of the obligations of a certification body in Art. 83(4)(b). This provision places a great responsibility on how certification bodies carry out their tasks, living up to requirements such as independence, integrity, and proper expertise. ${ }^{81}$ Furthermore, the same goes for controllers and processors that violate their obligations pursuant to certifications per Art. 42 and 43 GDPR. Thus, when those entities have violated in any manner the conditions of the granted certification are subject to the administrative fines imposed by the data protection authorities. In the case of the CSA, national cybersecurity certification authorities are competent to audit certification bodies, take appropriate measures in case of violations, and also supervise and enforce the rules of certification schemes against manufacturers and service providers, ${ }^{82}$ including impose penalties ${ }^{83}$. However, the amount of those administrative fines is at the discretion of each Member State, ${ }^{84}$ leading to potentially a wide range of pecuniary penalties. Despite the overall centralised approach, this 'open clause' in the CSA might pierce the veil of harmonisation and undermine the guarantees to prevent of forum-shopping offered by the common baseline rules, ${ }^{85}$ which is a substantial difference with the GDPR certification framework.

\footnotetext{
${ }^{74}$ Art. 42(1) GDPR, Art. 46(2) CSA.

${ }^{75}$ Art. 54(3) CSA.

${ }^{76}$ Recital 92 CSA.

77 See 3.2.

78 Art. 42(3), (4) GDPR

${ }^{79}$ Recital 100 GDPR.

${ }^{80}$ Article 29 Data Protection Working Party "Guidelines on the application and setting of administrative fines for the purposes of the Regulation 2016/679" WP 253 (October 2017), p.16. Read further Paul Nemitz, "Fines under the GDPR" in Data Protection and Privacy: The Internet of Bodies ed. Ronald Leenes et al. (Hart Publishing, 2018).

${ }^{81}$ Art. 43(2) (a-e) and Art. 43(1)(b) GDPR.

82 Art. 58(7)(a) CSA.

${ }^{83}$ Art. 58(8) (b-c) and (f) CSA.

${ }^{84}$ Art. 65 CSA.

85 See Section 2.2, p.5f.
} 


\section{Convergence}

The previous section discussed differences of the cybersecurity and the data protection certification frameworks, which point towards a divergent approach in the two Regulations, creating a gap between the frameworks that seems difficult to be bridged. This section focuses on the commonalities. One cannot speak of identical or tantamount elements, but it can be said with certainty that the data protection and the cybersecurity frameworks demonstrate aspects of convergence.

\subsection{Ex-ante transparency}

Taking one step back from the specific elements of each framework and reflecting on the rationales for introducing certification in the CSA and the GDPR, there is an underlying concept present in both frameworks: transparency; or rather, ex ante transparency. ${ }^{86}$ Certification is traditionally seen as an instrument offering transparency and increasing trust towards the certified object and organisation, as it may reduce information asymmetry in contracting parties, offer insights for audit purposes, assure the reliability of the counterpart seller, manufacturer, service provider. ${ }^{87}$

A certification first and foremost provides information to individuals, businesses, or the supervisory authorities about the certified data processing operations or the ICT product/service/process. Information is provided after the evaluation from an independent body, which offers more guarantees for the reliability of the provided information ${ }^{88}$ than a self-declaration. ${ }^{89}$ The GDPR certification framework, as mentioned earlier, explicitly assigns such a role to data protection certifications, especially helping data subjects assess the processing of controllers and processors. ${ }^{90}$ The CSA framework also refers to certification as offering transparency and awareness to citizens, organisations and businesses in relation cybersecurity issues and practices. ${ }^{91}$ The EDPB explained that documentation and communication of the results is important for certification to achieve the transparency goal, and recommended that at least the description of what was certified, the applicable criteria, the evaluation methodology and the duration of the certification should be public information. ${ }^{92}$ Prerequisite for a certification to function as a transparency tool is transparency of the certification (scope, evaluation methodology, criteria, complaint mechanisms etc.) itself, as hinted in Art. 42(3) GDPR.

Interestingly, both frameworks relate certification to embedding cybersecurity and data protection requirements 'by design'. In the CSA framework, security by design and the security requirements being fulfilled "during the entire lifecycle of the ICT product, ICT service or ICT process" are provided as security objectives of the cybersecurity

\footnotetext{
${ }^{86}$ Spagnuelo et. al characterised GDPR certifications as an ex ante transparency and awareness tool, helping users being aware of policies and practices, but not providing users with controls over the processing of data. Dayana Spagnuelo, Ana Ferreira, and Gabriele Lenzini, "Accomplishing transparency within the general data protection regulation." In 5th International Conference on Information Systems Security and Privacy (2018) p.6.

${ }^{87}$ Konrad Stahl and Roland Strausz, "Certification and market transparency." The Review of Economic Studies 84, no. 4 (2017): 1842-1868; Ali Sunyaev and Stephan Schneider, "Cloud services certification." Communications of the ACM 56, no. 2 (2013): 33-36. Also: Irene Kamara, Thordis Sveinsdottir, and Simone Wurster. "Raising trust in security products and systems through standardisation and certification: the CRISP approach." IEEE ITU Kaleidoscope: Trust in the Information Society (2015): pp. 1-7; Eric Lachaud, "What could be the contribution of certification to data protection regulation?" Doctoral dissertation (2019).

88 This is true provided that after certification is granted, the certifiers monitor whether the conditions for granting certification continue to be met, and have mechanisms in place to detect irregularities and nonconformities. See Chris Connolly, Graham Greenleaf, and Nigel Waters, "Privacy Self-Regulation in Crisis? -TRUSTe's 'Deceptive' Practices." Privacy Laws \& Business International Report 132 (2014): 13-17; Irene Kamara and Paul De Hert (2018).

89 Interested parties receive some information also from a mark or a seal. A seal is unique to a certification scheme and provides generic information on the type and scope of certification to which is related, and potentially a unique number connected to the specific processing operation certified.

90 Rec. 100 GDPR.

${ }^{91}$ Rec. 7 CSA.

92 EDPB (2019) pp. 19-20.
} 
certifications. ${ }^{93}$ The requirement that manufacturers qualify as applicants for certification enables the security by design approach. When a certified product is placed in the market, information regarding the security requirements met by the product is already made transparent and verified by an independent third party. ${ }^{94}$ The GDPR also refers to certification in relation to data protection by design and by default. ${ }^{95}$

In sum, both frameworks encourage early adoption of measures to comply with requirements, the conformity to which can be put forward via certification, contributing to ex ante transparency and increasing trust.

\subsection{Main actors in the implementation of the certification schemes: national authorities and conformity assessment bodies}

The analysed certification frameworks follow a similar approach in terms of governance of adopted or approved certifications, despite any differences in the development phase. The main actors are national supervisory authorities, namely the data protection authorities in the GDPR and the national cybersecurity certification authorities in the CSA ('competent public authorities'), and the certification bodies, which are private organisations. A role is also introduced for the National Accreditation Authorities, which are tasked to accredit certification bodies. ${ }^{96.97}$ The competent public authorities are granted investigative and corrective powers and tasks which place them in the centre of monitoring and supervision regarding certification. In addition, under both frameworks the competent public authorities have the power to issue certifications themselves.

\subsection{Data security as a common denominator}

Certification schemes under the GDPR have inevitably different scope than the ones under the CSA, since their legal basis differs. In addition, the object of certification in the data protection certification mechanisms is one or more processing operations, such as the collection, storage and erasure of personal data, ${ }^{98}$ while in the CSA cybersecurity certifications, it is ICT products, processes, or services. However, in normative terms, data security is a common denominator of the two certifications. As expected, security of information is at the core of the CSA certifications. Protection against accidental or unauthorised access, disclosure, processing, storage, destruction, loss or lack of availability lie among the core security objectives of the cybersecurity certification schemes. ${ }^{99}$

Furthermore, The GDPR aims at protecting the individual with regard to the processing of his or her personal information. As means to achieve this goal, the legislator introduces a

\footnotetext{
${ }^{93}$ Art. 51 CSA.

${ }^{94}$ See also Art. 46(2) CSA referring to certification attesting the availability, authenticity, integrity or confidentiality of data throughout the lifecycle of the ICT products, services, and processes.

${ }^{95}$ Art. 25(3) GDPR. However, both the obligation for compliance and the qualification to apply for certification concern controllers, not manufacturers. This issue was raised by the WP29, which pleaded for including manufacturers in the scope of Art. 25 GDPR. Article 29 Data Protection Working Party, 'The Future of Privacy.

Joint contribution to the Consultation of the European Commission on the legal framework for the fundamental right to protection of personal data' (2009) 02356/09/EN, WP168, para 45 (Article 29 Working Party, 'The Future of Privacy'). Read further: Lina Jasmontaite, Irene Kamara, Gabriela ZanfirFortuna, and Stefano Leucci, "Data protection by design and by default: Framing guiding principles into legal obligations in the GDPR" European Data Protection Law Review 4 (2018): 168.

96 This is the case for two out of the three accreditation models of Art. 43 GDPR. There is also the option for the data protection authorities to provide accreditation (43(1)(a) GDPR, but this is a model not endorsed by many MS in practice.

${ }^{97}$ Additionally, National Accreditation Bodies accredit public authorities which offer certification, as explained in 2.2, p. 4.

${ }_{98}$ Art. 42(1), (6) GDPR.

${ }^{99}$ Rt. 51(a), (b) CSA.
} 
range of sub-goals/provisions, such as data subjects' rights that empower the individual, but also security of processing that guarantees the protection personal data, and by doing so, contributes to the protection of the individual. It can be asserted therefore, that security of processing is one of the provisions that aim at materialising the sub-goal of protecting information (or more accurately personal data) in the GDPR, and through that, the individual. In parallel, the GDPR assigns weight on (personal) data security by elevating it to a general principle, which did not exist under the Directive 95/46/EC. ${ }^{100}$ Article 5(1)(f) introduces a principle of integrity and confidentiality which relates to common information security principles ${ }^{101}$ and creates a duty to secure personal data. ${ }^{102}$ The principle of Art. 5(f), refers to protection against unauthorised or unlawful processing, accidental loss, destruction or damage, and provides that personal data should be processed "in a manner that ensures appropriate security" using "appropriate technical or organisational measures". ${ }^{103}$ Unauthorised or unlawful processing includes access or use of personal data, but also the equipment used for processing. ${ }^{104}$ Following that, security of processing is a legal obligation for controllers and processors, compliance to which may be demonstrated with certification. ${ }^{105}$ Although GDPR certifications most likely will -but not necessarily- involve data security requirements, and the CSA certifications focus exclusively on it, data security can be a common ground for both laws, and by extension, certifications. ${ }^{106}$

\section{Discussion}

Overall, the comparison revealed different certification models at their core, governed and supervised in a similar manner. ${ }^{107}$ Several normative and policy reasons both internal, thus attributed to the law and its protected rights, but also external, such as the certification market maturity, explain the divergence.

An internal reason of normative nature relates to the design of the examined Union laws. While the GDPR is a Regulation introducing a framework with principles, obligations, and rights for regulatees and individuals, the CSA contains only organisational and procedural provisions such as the provisions around the role of ENISA. This practically means that certification in the case of the GDPR already has a solid normative basis as a starting point for the certification criteria of the scheme. The CSA schemes however need to rely on external to the legal framework sources, such as technical standards, which may or may not have been developed with the Union policy and legal framework on cybersecurity and information security in mind. ${ }^{108}$ To ensure thus a high degree of harmonisation, the legislator in the case of the CSA needed to centralise the decisions and the development of the schemes.

Another reason relates to the role of certification in the Regulations: while in the GDPR certification is a voluntary instrument to demonstrate compliance with legal obligations, the CSA certifications, albeit also in principle voluntary, may become mandatory in

\footnotetext{
100 The wording of the principle mirrors however Art. 17 of the Directive 95/46/EC. Cécile De Terwagne "Commentary Article 5" in, The EU General Data Protection Regulation. A commentary, eds.

Christopher Kuner, Lee Bygrave, and Christopher Docskey (Oxford University Press, 2020), p. 318.

101 Spyridon Samonas and David Coss. "The CIA strikes back: Redefining confidentiality, integrity and availability in security." Journal of Information System Security 10, no. 3 (2014).

102 Pieter Wolters, "The security of personal data under the GDPR: a harmonized duty or a shared responsibility?" International Data Privacy Law 7, no. 3 (2017): 165-178.

103 Art. 5(1)(f) GDPR.

104 Recital 39 GDPR.

105 Art. 32(3) GDPR.

106 Read further an ENISA study on data security measures under the GDPR and the bridges between Art. 32 GDPR and information security legislation. ENISA, "Handbook on security of personal data processing", (ENISA, 2017).

107 Comparative overview in Table 1, p.12.

${ }^{108}$ ENISA, "Standards supporting certification. Analysis of Standards in Areas Relevant to the Potential EU Candidate Cybersecurity Certification Schemes" (ENISA, 2019).
} 
Member States with national technical regulations or with a Union law. ${ }^{109}$ The importance of harmonised scheme content is heightened, and is better ensured in a centralised than a decentralised certification framework. Furthermore, the maturity in the cybersecurity certification market and the abundance of certifications as opposed to the growing data protection certification market, explains the level of detail in the CSA rules and equal attention to the content of certifications and to the development and governance, as opposed to the primary focus of the GDPR certification framework on the actors, their powers, and supervision. ${ }^{110}$ The absence of detail regarding the content of the criteria and certification schemes in the GDPR is compensated with a number of safeguards such as the thorough provisions on accreditation, which ensure the competence of the conformity assessment bodies, the mandatory approval of the criteria by the supervisory authority, and the powers of the Commission to adopt delegated acts on the criteria and requirements of the data protection certification models. ${ }^{111}$

Another difference is the scalability of the certifications. The CSA endorses clearly granularity in several aspects such as the assurance levels and the first party conformity assessment. On the other hand, the GDPR mentions risk based approach and makes a reference to the needs of SMEs when it comes to certification, but does not seem to fully embrace a granular approach. This can be attributed to the fact that a granular approach implies acceptance of some-non-conformities and risks being residual; this possibly contradicts the aim of the GDPR to protect the rights and freedoms of the individuals, which should be balanced, and restricted only under conditions. In addition, first party assessments in the GDPR for conforming to fundamental rights-related requirements would have been a contradiction in itself.

Comparing the certification frameworks in terms of penalties and fines, the GDPR adopts a stricter and more regulated approach than the CSA, which includes an opening clause for MS in that matter. While one would have expected a more streamlined approach in the Cybersecurity Act due to the focus on centralisation and harmonisation, the GDPR approach is fully justified mostly from a policy perspective: certification is relatively novel in data protection, it is introduced for the first time in the Union data protection law, and most importantly the GDPR introduces high fines for the infringements of its provisions, and certification could not be the exception.

Nonetheless, the comparative analysis also revealed convergence. Considering the similarities, those occur where the goals of the CSA and the GDPR converge, but also for organisational efficiency reasons. ${ }^{112}$ Data security, as well as data protection and security by design, are fundamental concepts for both data protection and cybersecurity. Thus, where the norms converge, the certification frameworks converge as well and the resulting certifications may be aligned. Alignment does not mean overlap. Taking the example of data security: cybersecurity obviously has broader material scope not limited only to personal data security, but of any type of information. And personal data protection is multifaceted, security being only one of the facets in addition to fairness and lawfulness, data minimisation and purpose specification, accountability, and shielding individuals with substantial and procedural rights. Nonetheless, data security is a topos, on which certification to be developed in both fields can rely and interlink with one another. In addition, the aim of certification as a transparency mechanism is present in both the cybersecurity certification framework and the data protection certification mechanisms. Certification is presumed to respond to the proclaimed need for

${ }^{109}$ Recitals 91 and 92, Art. 1(1), Art. 56 CSA and Art. 67 (3) CSA. See: Dennis-Kenji Kipker, "EU Cybersecurity Act und Certification Schemes: ein aktueller Fortschrittsbericht." Datenschutz und Datensicherheit-DuD 44, no. 4 (2020): 263-265.

110 The object of certification being the processing operation(s) and potential subject matters are provided in Art. 42 and 24, 28, 32, 46 GDPR.

111 Art. 43(8) GDPR. See analysis in Kamara et al. (2019).

112 For discussion on points of interaction between the NIS Directive and the GDPR read: Markopoulou, D. et al. (2019) ibid; for an overview of concepts and values clusters and conflicts in cybersecurity see Ibo van de Poel "Core Values and Value Conflicts in Cybersecurity: Beyond Privacy Versus Security." In The Ethics of Cybersecurity, (Springer, Cham, 2020) p.45f. 
transparency through third party audits and publication of information regarding the audited object. ${ }^{113}$

As regards governance, public authorities are strengthened with powers to supervise conformity assessment bodies and act as one, in both frameworks. Accredited certification bodies, conduct the process, and monitor the post-certification phase. The centralised approach of the CSA in the development phase of the schemes, gives its place to a more distributed model, similar to the GDPR certification mechanisms, in the implementation phase. And because in both laws and certification frameworks, consistency and harmonisation is of high importance, the distributed models, whereby national authorities take over pivotal roles, are designed with embedded guarantees such as a consistency mechanism and notification obligations. ${ }^{114} \mathrm{~A}$ closer look, reveals that policy and organisational reasons prompted the legislator to those choices in both frameworks; national authorities have a better control of supervision and enforcement in their jurisdictions than a Union agency or the Commission.

Overall, the adopted models for certification frameworks in the CSA and the GDPR can be explained by the underlying values and goals between data protection and cybersecurity, as expressed in the GDPR and the CSA respectively. As demonstrated by the legal foundations of the CSA and the GDPR, while both laws might qualify at large as 'information protection laws', the CSA is ultimately an Internal Market legal instrument aiming at approximation of laws for the establishment and functioning of the internal market, ${ }^{115}$ while the GDPR protects individuals with regard to the processing of their personal data, ${ }^{116}$ thus is concerned primarily with fundamental rights and freedoms. ${ }^{117}$

\begin{tabular}{|c|c|c|c|c|}
\hline Type of component & CSA framework & CSA Article & GDPR mechanisms & $\begin{array}{l}\text { GDPR } \\
\text { Article }\end{array}$ \\
\hline Object of certification & $\begin{array}{l}\text { ICT products, ICT } \\
\text { process, ICT } \\
\text { services or groups } \\
\text { thereof }\end{array}$ & Rec. 73 & $\begin{array}{l}\text { Data processing } \\
\text { operation(s) }\end{array}$ & Art. 42 \\
\hline $\begin{array}{l}\text { Type of conformity } \\
\text { assessment }\end{array}$ & $\begin{array}{l}\text {-Third party } \\
\text { certification } \\
\text {-Conformity self- } \\
\text { assessment by } \\
\text { manufacturer or } \\
\text { provider also } \\
\text { possible for low } \\
\text { complexity/low risk } \\
\text { situations with EU } \\
\text { statement of } \\
\text { conformity }\end{array}$ & $\begin{array}{l}\text { Rec. } 79 \\
\text { Rec. } 80 \\
\text { Rec. } 82 \\
\text { Art. } 53 \\
\text { Art. } 56\end{array}$ & Third party certification & Art. 43 \\
\hline Voluntary/mandatory & $\begin{array}{l}\text { Voluntary in } \\
\text { principle, mandatory }\end{array}$ & $\begin{array}{l}\text { Rec. } 91 \\
\text { Rec. } 92\end{array}$ & Voluntary & Art. 42 \\
\hline
\end{tabular}

113 It should be noted that the role of certification as a transparency mechanism has its limitations, as for example only the results of a successful certification process are published.

${ }^{114}$ Art. 63 GDPR, and Art. 61 CSA (Notification obligation of the national cybersecurity certification authorities towards the European Commission).

${ }^{115}$ CSA Preamble. Art. 114 Treaty on the Functioning of the European Union (TFEU). Moreover, the approach of the Union in regulating cybersecurity has been criticised for its blurry role in protecting fundamental rights and freedoms. Gloria González Fuster and Lina Jasmontaite, "Cybersecurity Regulation in the European Union: The Digital, the Critical and Fundamental Rights." In The Ethics of Cybersecurity, eds. Markus Christen, Bert Gordijn, Michele Loi, pp. 97-115 (Springer, Cham, 2020) p. 113.

116 GDPR Preamble. Art. 16 TFEU.

117 D. Markopoulou et al. argue that due to the legal foundation of the GDPR on Art. 16TFEU, which establishes a horizontal legal obligation to protection the right to data protection, in a conflict between cybersecurity and data protection, the latter would prevail in a balancing test between the two. Dimitra Markopoulou, Vagelis Papakonstantinou, and Paul de Hert. "The new EU cybersecurity framework: The NIS Directive, ENISA's role and the General Data Protection Regulation." Computer Law \& Security Review 35, no. 6 (2019): 105336, p.10f 


\begin{tabular}{|c|c|c|c|c|}
\hline & also possible in MS & Art. 56 & & \\
\hline Geographical scope & $\begin{array}{l}\text { Only Union level, no } \\
\text { national } \\
\text { certifications under } \\
\text { the CSA } 118\end{array}$ & Art. 57 & $\begin{array}{l}\text { Union level (European } \\
\text { Data Protection Seal) and } \\
\text { national certifications }\end{array}$ & Art. 42 \\
\hline $\begin{array}{l}\text { Minimum scheme } \\
\text { content }\end{array}$ & $\begin{array}{l}\text { Yes, provided in the } \\
\text { CSA }\end{array}$ & $\begin{array}{l}\text { Rec. } 84 \\
\text { Art. } 51\end{array}$ & $\begin{array}{l}\text { Not provided in the } \\
\text { GDPR, COM delegated } \\
\text { act possible or up to the } \\
\text { scheme drafter }\end{array}$ & Art. 43 \\
\hline Mutual recognition & $\begin{array}{l}\text { Yes, throughout the } \\
\text { Union. } \\
\text { (Peer review system } \\
\text { across national } \\
\text { cybersecurity } \\
\text { certification } \\
\text { authorities) }\end{array}$ & $\begin{array}{l}\text { Rec. } 73 \\
\text { Rec. } 99\end{array}$ & No & $\mathrm{N} / \mathrm{A}$ \\
\hline Granularity & $\begin{array}{l}\text { Three assurance } \\
\text { levels (basic - } \\
\text { substantial - high) } \\
\text { for certification. } \\
\text { Conformity self- } \\
\text { assessment: only } \\
\text { basic }\end{array}$ & $\begin{array}{l}\text { Rec. } 77 \\
\text { Rec. } 86 \\
\text { Rec. } 88 \\
\text { Art. } 52 \\
\text { Art. } 56\end{array}$ & $\begin{array}{l}\text { Not determined in the } \\
\text { GDPR, } \\
\text { At the discretion of the } \\
\text { scheme drafter }\end{array}$ & $\mathrm{N} / \mathrm{A}$ \\
\hline & $\begin{array}{l}\text { Evaluation levels } \\
\text { also possible }\end{array}$ & & & \\
\hline Transparency & $\begin{array}{l}\text { Website with } \\
\text { schemes } \\
\text { maintained by } \\
\text { ENISA } \\
\text { National authorities } \\
\text { notify COM on } \\
\text { accredited } \\
\text { conformity } \\
\text { assessment bodies } \\
\text { Penalties in national } \\
\text { laws notified to } \\
\text { COM }\end{array}$ & $\begin{array}{l}\text { Rec. } 85 \\
\text { Art. } 50 \\
\text { Art. } 61 \\
\text { Art. } 65\end{array}$ & $\begin{array}{l}\text { Registry maintained by } \\
\text { the EDPB and supervisory } \\
\text { authorities }\end{array}$ & $\begin{array}{l}\text { Rec. } \\
100 \\
\text { Art. } 42\end{array}$ \\
\hline $\begin{array}{l}\text { Supervision \& } \\
\text { enforcement }\end{array}$ & $\begin{array}{l}\text { By national } \\
\text { cybersecurity } \\
\text { certification } \\
\text { authorities }\end{array}$ & $\begin{array}{l}\text { Rec. } 73 \\
\text { Rec. } 102 \\
\text { Art. } 58\end{array}$ & $\begin{array}{l}\text { By certification bodies and } \\
\text { national supervisory } \\
\text { authorities (DPA) }\end{array}$ & Art. 43 \\
\hline Consistency & $\begin{array}{l}\text { European } \\
\text { Cybersecurity } \\
\text { Certification Group } \\
\text { (ECCG) }\end{array}$ & Rec. 103 & $\begin{array}{l}\text { GDPR consistency } \\
\text { mechanism }\end{array}$ & \\
\hline Revision & $\begin{array}{l}\text { Every } 5 \text { years, } \\
\text { evaluation by } \\
\text { ENISA }\end{array}$ & Art. 49 & $\begin{array}{l}\text { Not mentioned, in the } \\
\text { GDPR. } \\
\text { Re- } \\
\text { certification every } 3 \text { years. }\end{array}$ & Art. 43 \\
\hline
\end{tabular}

Table 1: Comparative overview of certification rules under the Cybersecurity Act and the General Data Protection Regulation

\section{Concluding remarks}

The article started with the assumption that the Union cybersecurity and data protection laws both aim, inter alia, at protecting information. Because of this connection, the way some issues are regulated in those laws should be similar. The Chapter was examined to which extent, a private law voluntary instrument -certification- is introduced and regulated in an aligned or misaligned manner in the GDPR and CSA. The comparative analysis, identifying both similarities and differences, showed that the CSA and the GDPR follow different models in both the development and the governance and

\footnotetext{
${ }_{118}$ National cybersecurity certification schemes are replaced by a European cybersecurity certification scheme (Rec. 85 CSA).
} 
implementation phases: a centralised certification managed by one authority, developed with the consultation of stakeholders in the CSA, national certifications in parallel to Union level ones, developed by any interested party in the GDPR; the possibility of selfassessments in the CSA versus strictly third party assessments in the GDPR; regulated legal effects in the CSA versus implied market benefits in the GDPR; and, mutual recognition of certificates in all Member States in the CSA versus a re-assessment requirement in each Member State in the GDPR, to mention some of the differences in the frameworks for certification in the two Regulations.

The analysis showed that differences are mostly mandated by the nature, goals, and legal basis of the two Union laws. While indeed the CSA and the GDPR both serve to some extent a goal of protecting information, such a classification does not give due account to other important aspects of these laws, which are significant enough to influence their legal design, including their approach to seemingly less impactful provisions, such as those of voluntary private law instruments. Thus, the protected values and the legal bases of the CSA and the GDPR have impacted the legal design of certification frameworks. The common denominators from a normative perspective (e.g. personal data security, security of equipment, integrity and confidentiality), as well as the decentralised governance approach with embedded harmonisation and consistency mechanisms, offer common grounds for interaction. The form of this interaction in practical terms can manifest itself in various ways: common baseline criteria and requirements, partial mutual recognition, joint certification or accreditation evaluations, combined transparency registries, and others. From the perspective of both the regulated companies and the individuals, the rights of which are affected, the interaction and perhaps channels of collaboration in certification, demonstrable in practice, are necessary, to avoid the negative externalities, as long as the protected values in each law are not undermined. To conclude with, one cannot speak of 'misaligned laws', but justified divergent approaches, that do not exclude interaction when implementing the frameworks. 


\section{Bibliography}

Article 29 Data Protection Working Party. "Guidelines on the application and setting of administrative fines for the purposes of the Regulation 2016/679" WP 253 (October 2017).

Colombo, Carlo, and Mariolina Eliantonio. "Harmonized technical standards as part of EU law: Juridification with a number of unresolved legitimacy concerns? Case C-613/14 James Elliot Construction Limited v. Irish Asphalt Limited, EU: C: 2016: 821." Maastricht Journal of European and Comparative Law 24, no. 2 (2017): 323-340.

De Terwagne, Cécile. 'Commentary Article 5" in, The EU General Data Protection Regulation. A commentary, eds. Christopher Kuner, Lee Bygrave, and Christopher Docskey (Oxford University Press, 2020).

Directive (EU) 2016/680 of the European Parliament and of the Council of 27 April 2016 on the protection of natural persons with regard to the processing of personal data by competent authorities for the purposes of the prevention, investigation, detection or prosecution of criminal offences or the execution of criminal penalties, and on the free movement of such data, and repealing Council Framework Decision 2008/977/JHA OJ L 119, 4.5.2016.

ENISA. "Handbook on security of personal data processing", (ENISA, 2017).

ENISA. "Recommendations on European Data Protection Certification" (ENISA 2017).

ENISA. "Standards supporting certification. Analysis of Standards in Areas Relevant to the Potential EU Candidate Cybersecurity Certification Schemes" (ENISA, 2019).

European Commission. "Data protection as a pillar of citizens' empowerment and the EU's approach to the digital transition - two years of application of the General Data Protection Regulation" Communication from the Commission to the European Parliament and the Council (2020) COM (2020) 264 final.

European Commission. "Proposal for a of the European Parliament and of the Council concerning the respect for private life and the protection of personal data in electronic communications and repealing Directive 2002/58/EC (Regulation on Privacy and Electronic Communications)" COM (2017) 010 final.

European Commission. "Proposal for a Regulation of the European Parliament and of the Council on ENISA, the "EU Cybersecurity Agency", and Repealing Regulation (EU) 526/2013, and on Information and Communication Technology Cybersecurity Certification ("Cybersecurity Act"), COM (2017) 477 final.

European Data Protection Board. "Guidelines 1/2018 on certification and identifying certification criteria in accordance with Articles 42 and 43 of the Regulation", v.3 2019.

European Parliament. Legislative resolution of 12 March 2019 on the proposal for a regulation of the European Parliament and of the Council on ENISA, the "EU Cybersecurity Agency", and repealing Regulation (EU) 526/2013, and on Information and Communication Technology cybersecurity certification ("Cybersecurity Act") (COM (2017)0477 - C8-0310/2017 - 2017/0225(COD)).

González Fuster, Gloria, and Lina Jasmontaite. "Cybersecurity Regulation in the European Union: The Digital, the Critical and Fundamental Rights." In The Ethics of Cybersecurity, eds. Markus Christen, Bert Gordijn, Michele Loi, pp. 97-115 (Springer, Cham, 2020).

Hornung, Gerrit. "A General Data Protection Regulation for Europe: Light and Shade in the Commission's Draft of 25 January 2012." SCRIPTed 9 (2012): 64.

ISO/IEC 17000 Conformity assessment — Vocabulary and general principles. 
ISO/IEC 17065:2012 Conformity assessment - Requirements for bodies certifying products, processes and services.

Jasmontaite, Lina, Irene Kamara, Gabriela Zanfir-Fortuna, and Stefano Leucci. "Data protection by design and by default: Framing guiding principles into legal obligations in the GDPR" European Data Protection Law Review 4 (2018): 168-189.

Kamara Irene and Paul De Hert. "Data protection certification in the EU: Possibilities, actors and building blocks in a reformed landscape." In Privacy and data protection seals, eds. Rowena Rodrigues and Vagelis Papakonstantinou, pp. 7-34. TMC Asser Press, The Hague, 2018.

Kamara, Irene, Ronald Leenes, et al. "Data protection certification mechanisms: Study on Articles 42 and 43 of the Regulation (EU) 2016/679. Final Report" Publications Office of the EU (2019)

Kamara, Irene, Ronald Leenes, et al. "Data protection certification mechanisms: Study on Articles 42 and 43 of the Regulation (EU) 2016/679. Annexes" Publications Office of the EU (2019)

Kamara, Irene. "Commentary Article 40" in The European General Data Protection Regulation (GDPR) A Commentary, ed. Christopher Kuner, Lee Bygrave, and Christopher Docksey, (Oxford University Press 2020).

Kamara, Irene, Thordis Sveinsdottir, and Simone Wurster. "Raising trust in security products and systems through standardisation and certification: the CRISP approach" IEEE ITU Kaleidoscope: Trust in the Information Society (2015): pp. 1-7

Kipker, Dennis-Kenji. "EU Cybersecurity Act und Certification Schemes: ein aktueller Fortschrittsbericht." Datenschutz und Datensicherheit-DuD 44, no. 4 (2020): 263-265.

Lachaud, Eric. "What could be the contribution of certification to data protection regulation?" Doctoral dissertation (2019).

Markopoulou, Dimitra, Vagelis Papakonstantinou, and Paul de Hert. "The new EU cybersecurity framework: The NIS Directive, ENISA's role and the General Data Protection Regulation." Computer Law \& Security Review 35, no. 6 (2019): 105336.

Matheu, Sara N., Jose L. Hernandez-Ramos, and Antonio F. Skarmeta. "Toward a cybersecurity certification framework for the Internet of Things." IEEE Security \& Privacy 17, no. 3 (2019): 66-76.

Mitrakas, Andreas. "The emerging EU framework on cybersecurity certification." Datenschutz und Datensicherheit-DuD 42, no. 7 (2018): 411-414.

Nemitz, Paul. "Fines under the GDPR" in Data Protection and Privacy: The Internet of Bodies ed. Ronald Leenes et al. (Hart Publishing, 2018).

Peers Steve and Marios Costa. "Accountability for delegated and implementing acts after the Treaty of Lisbon." European Law Journal 18, no. 3 (2012): 427-460.

Regulation (EU) 2016/679 of the European Parliament and of the Council of 27 April 2016 on the protection of natural persons with regard to the processing of personal data and on the free movement of such data, and repealing Directive 95/46/EC (General Data Protection Regulation, OJ L 119, 4.5.2016.

Rodrigues, Rowena, David Barnard-Wills, Paul De Hert, and Vagelis Papakonstantinou. "The future of privacy certification in Europe: an exploration of options under article 42 of the GDPR." International Review of Law, Computers \& Technology 30, no. 3 (2016): 248270.

Samonas, Spyridon, and David Coss. "The CIA strikes back: Redefining confidentiality, integrity and availability in security." Journal of Information System Security 10, no. 3 (2014): 21-45. 
Senden, Linda. "The Constitutional Fit of European Standardization Put to the Test." Legal Issues of Economic Integration 44, no. 4 (2017): 337-352.

Spagnuelo, Dayana, Ana Ferreira, and Gabriele Lenzini. "Accomplishing transparency within the general data protection regulation." In 5th International Conference on Information Systems Security and Privacy. (2018)

Stahl, Konrad, and Roland Strausz. "Certification and market transparency." The Review of Economic Studies 84, no. 4 (2017): 1842-1868.

Sunyaev Ali and Stephan Schneider. "Cloud services certification." Communications of the ACM 56, no. 2 (2013): 33-36.

van de Poel, Ibo. "Core Values and Value Conflicts in Cybersecurity: Beyond Privacy Versus Security." In The Ethics of Cybersecurity, pp. 45-71. Springer, Cham, 2020.

Van der Sloot, Bart, and Eleni Kosta. "Big brother watch and others v UK: Lessons from the latest Strasbourg ruling on bulk surveillance", European Data Protection Law Review 5, No. 2, p. $252-261$

Van Hoecke, Mark. " Methodology of comparative legal research" Law and Method (2015): 1-35.

Weber Rolf $\mathrm{H}$. and Evelyne Studer. "Cybersecurity in the Internet of Things: Legal aspects." Computer Law \& Security Review 32, no. 5 (2016): 715-728.

Wolters, Pieter. "The security of personal data under the GDPR: a harmonized duty or a shared responsibility?" International Data Privacy Law 7, no. 3 (2017): 165-178. 